\title{
Chronic Kidney Disease and Risk of Death from Infection
}

\author{
Henry E. Wang ${ }^{a}$ Christopher Gamboab David G. Warnock ${ }^{c}$ Paul Muntner ${ }^{\text {b, }}$ \\ Departments of a Emergency Medicine and ${ }^{b}$ Epidemiology, and ${ }^{c}$ Division of Nephrology, Department of Medicine, \\ University of Alabama at Birmingham, Birmingham, Ala., USA
}

\section{Key Words}

Chronic kidney disease $\cdot$ Infection $\cdot$ Sepsis $\cdot$ Mortality

\begin{abstract}
Background: Infection, bacteremia and sepsis are major sources of morbidity and mortality in patients with endstage renal disease. This study sought to determine the association between predialysis chronic kidney disease (CKD) and infection-related mortality. Methods: We analyzed participants in the Third National Health and Nutrition Examination Survey (NHANES III). The study included adults $\geq 45$ years-old without end-stage renal disease. Estimated glomerular filtration rate (eGFR) was categorized as $\geq 60$, $45-59.9$ and $<45 \mathrm{ml} / \mathrm{min}$ per $1.73 \mathrm{~m}^{2}$, and urinary albuminto-creatinine ratio (ACR) as $<30,30-299.9$ and $\geq 300 \mathrm{mg} / \mathrm{g}$. The study identified infection-related mortality, including septicemia, respiratory, abdominal and gastrointestinal, cardiac, kidney and genitourinary, neurologic, and other infections over a median of 13 years using the National Death Index. Results: Of 7,400 participants included in the study, 206 died from infections. Compared to individuals with eGFR $\geq 60 \mathrm{ml} / \mathrm{min}$ per $1.73 \mathrm{~m}^{2}$, infection-related mortality was higher for those with lower eGFR [adjusted HR $=1.36(95 \%$ Cl: $0.81,2.30)$ and $2.36(1.04,5.38)$ for eGFR of $45-59.9$ and $<45 \mathrm{ml} / \mathrm{min}$ per $1.73 \mathrm{~m}^{2}$, respectively; $\mathrm{p}$ trend $=0.06$ ]. Compared to individuals with $A C R<30 \mathrm{mg} / \mathrm{g}$, infection-related mortality was higher for ACR levels of 30-299 and $\geq 300$ $\mathrm{mg} / \mathrm{g}$ [adjusted $\mathrm{HR}=1.68(95 \% \mathrm{Cl}: 0.97,2.92)$ and $2.84(0.92$,
\end{abstract}

8.74), $\mathrm{p}$ trend $=0.02]$. Conclusions: Reduced eGFR and albuminuria are associated with increased risk for infection-related mortality. Efforts are needed to reduce its incidence and mitigate the effects of infections among individuals with CKD.

Copyright $\odot 2011$ S. Karger AG, Basel

\section{Introduction}

Chronic kidney disease (CKD) is a major public health problem affecting approximately $11.5 \%$ of US adults [1]. CKD is associated with poor outcomes including an increased risk of kidney failure, cardiovascular disease and mortality [1-4]. These associations may result from the presence of traditional risk factors as well as biochemical abnormalities such as increased inflammatory factors, endothelial dysfunction and enhanced coagulation [3].

Microbial infection may result in bacteremia, triggering exaggerated inflammation and sepsis [5]. Infection, bacteremia and sepsis are major sources of morbidity and mortality in patients with end-stage renal disease receiving chronic hemodialysis therapy [6, 7]. For example, using the US Renal Data System, Powe et al. [7] found that during 7 years of follow-up, $11.7 \%$ of all hemodialysis patients and $9.4 \%$ of peritoneal dialysis patients had at least one episode of septicemia, and Sarnak and Jaber [6] found that the sepsis mortality was 100 - to 300-times higher for chronic dialysis patients than the general public. Hypoth-

\section{KARGER}

(C) 2011 S. Karger AG, Basel

Fax +41613061234 E-Mail karger@karger.ch www.karger.com www.karger.com/ajn
Henry E. Wang, MD, MS

Department of Emergency Medicine, University of Alabama at Birmingham

619 19th Street South, OHB 251

Birmingham, AL 35249 (USA)

Tel. +1 205996 6526, E-Mail hwang@ uabmc.edu 
esized reasons for this association include increased susceptibility to infection, the presence of comorbidities such as diabetes, and repetitive exposure to pathogens during hemodialysis.

In contrast to the approximately 500,000 dialysis patients, over 20 million US adults have CKD $[1,8]$. An important unanswered question is whether the increased risk of infection and infection-associated mortality extends from dialysis patients to the much larger population of patients with predialysis CKD. An association between earlier stages of CKD and infection or infection-associated mortality has important implications for clinical care, pointing to infection prevention and mitigation as important strategies for reducing mortality in this population.

The objective of this study was to determine the association between moderate-to-severe CKD and death attributed to infection. To address this objective, we evaluated the association of reduced estimated glomerular filtration rate (eGFR) and increased albuminuria with infection-related mortality in the general US population $\geq 45$ years of age using data from the Third National Health and Nutrition Examination Survey (NHANES III) Mortality Follow-Up Study.

\section{Materials and Methods}

\section{Study Design and Setting}

The protocol for NHANES III was approved by the Institutional Review Board of the National Center for Health Statistics of the Centers for Disease Control and Prevention. All participants gave written informed consent. The Institutional Review Board of the University of Alabama at Birmingham determined the analysis of NHANES III data to be exempt research.

NHANES III was conducted by the National Center for Health Statistics of the Centers for Disease Control and Prevention [9]. Few infection-related deaths occurred among adults $<45$ years of age. Therefore, we limited the current analysis to participants $\geq 45$ years of age. Between 1988 and 1994, 9,787 adults 45 years of age and older participated in NHANES III.

\section{Baseline Data Collection}

NHANES III baseline data were collected during an in-home interview and a subsequent visit to a mobile examination center (National Center for Health Statistics 1994). Information on demographics, education, cigarette smoking and physical activity were collected using a standardized questionnaire. Blood pressure and waist circumference to the nearest $0.1 \mathrm{~cm}$ were measured during the in-home interview and/or participant visit to the mobile examination center.

We used serum and urine laboratory assay values as obtained and reported by NHANES $[9,10]$. Serum C-reactive protein (CRP) was quantified using latex-enhanced nephelometry, a low sensitivity assay. Since a large proportion of participants had CRP values below the limit of detection, we categorized participants as having CRP $<3.0$ (i.e. below the limit of detection), between 3.0 and 9.9 , or $\geq 10.0 \mathrm{mg} / \mathrm{l}$. We defined diabetes mellitus as a fasting plasma glucose $\geq 126 \mathrm{mg} / \mathrm{dl}$, a nonfasting plasma glucose $\geq 200$ $\mathrm{mg} / \mathrm{dl}$ and/or a self-reported history of diabetes with concurrent use of antidiabetes medication. eGFR was calculated using the Chronic Kidney Disease Epidemiology Collaboration equation and categorized as $\geq 60,45-59.9$ and $<45 \mathrm{ml} / \mathrm{min}$ per $1.73 \mathrm{~m}^{2}$ [11]. Urinary albumin-to-creatinine ratio (ACR) was categorized as $<30,30$ to 299.9 and $\geq 300 \mathrm{mg} / \mathrm{g}$.

\section{Outcomes and Covariates}

The primary outcome was death due to infection. Adult NHANES III participants were followed for mortality through December 31, 2006. Probabilistic matching was used to link NHANES III participants with the National Death Index to ascertain vital status and cause of death [9]. The National Death Index is a central index of death record information from all US states, including information on the underlying cause of death as reported by the certifying physician. Probabilistic matching was based on 12 identifiers for each participant (e.g. Social Security number, sex, date of birth) [12].

The International Statistical Classification of Diseases, Injuries and Causes of Death (ICD) revision 9 was used for classifying deaths occurring between 1988 and 1998, and ICD revision 10 (ICD-10) for deaths occurring between 1999 and 2006. Prior studies of hospital discharge and mortality data have used ICD-9 and ICD-10-based taxonomies to identify infection-related diagnoses and deaths $[13,14]$. Using this strategy, we identified cause of death categories related to infections, including septicemia, respiratory (e.g. pneumonia), abdominal and gastrointestinal (e.g. appendicitis, diverticulitis), cardiac (e.g. endocarditis), kidney and genitourinary (e.g. pyelonephritis, pelvic inflammatory disease), neurologic (meningitis), and other infections (online suppl. Appendix 1, www.karger.com/doi/10.1159/000330673). Based on the available data, we could not distinguish hospital or institutionalacquired infections.

Follow-up for each study participant consisted of the time between their NHANES III examination and the date of death. Follow-up was censored at December 31, 2006 for those who did not die.

\section{Data Analysis}

We defined baseline eGFR by the categories $\geq 60,45-59.9$ and $<45 \mathrm{ml} / \mathrm{min} / 1.73 \mathrm{~m}^{2}$ and albuminuria by the categories $<30,30-$ 299.9 and $\geq 300 \mathrm{mg} / \mathrm{g}$. Using Cox proportional hazards regression models, we calculated hazard ratios for infection-related mortality associated with eGFR and ACR. Initial models included adjustment for age (using a linear spline with a knot at 60 years of age), race/ethnicity and sex. Subsequent models included additional adjustment for tobacco use, waist circumference, total cholesterol, hypertension, diabetes mellitus, history of stroke or myocardial infarction CRP, serum phosphorus, serum albumin, and serum $25(\mathrm{OH}) \mathrm{D}$. We also fit a multivariable model with additional adjustment for log-transformed ACR and eGFR. To test for linear trends across levels of eGFR and ACR, we included the median eGFR and ACR value within each eGFR and ACR level as a continuous variable in the Cox regression models.

Finally, we fit a multivariable-adjusted Cox regression model with cross-categorized eGFR and ACR. For this final analysis, we a priori grouped those with eGFR levels of $45-59.9$ and $<45 \mathrm{ml} /$ 
Table 1. Baseline characteristics of adult participants in the Third NHANES by level of eGFR and albuminuria

\begin{tabular}{|c|c|c|c|c|c|c|}
\hline \multirow[t]{2}{*}{ Characteristic } & \multicolumn{3}{|c|}{$\mathrm{eGFR}, \mathrm{ml} / \mathrm{min} / 1.73 \mathrm{~m}^{2}$} & \multicolumn{3}{|l|}{ ACR, mg/g } \\
\hline & $\begin{array}{l}\geq 60 \\
(n=6,404)\end{array}$ & $\begin{array}{l}45-59 \\
(n=687)\end{array}$ & $\begin{array}{l}<45 \\
(\mathrm{n}=309)\end{array}$ & $\begin{array}{l}<30 \\
(\mathrm{n}=6,097)\end{array}$ & $\begin{array}{l}30-299 \\
(n=1,059)\end{array}$ & $\begin{array}{l}\geq 300 \\
(\mathrm{n}=244)\end{array}$ \\
\hline Age, years & $59.3(0.3)$ & $72.8(0.6)$ & $74.3(0.8)$ & $59.9(0.3)$ & $65.7(0.7)$ & $67.1(1.3)$ \\
\hline \multicolumn{7}{|l|}{ Race/ethnicity } \\
\hline White & 81.9 & 85.7 & 86.0 & 83.3 & 77.3 & 65.4 \\
\hline Black & 8.3 & 7.4 & 9.5 & 7.6 & 11.8 & 19.1 \\
\hline Mexican-American & 3.4 & 1.1 & 1.4 & 3.1 & 3.6 & 5.8 \\
\hline Other & 6.4 & 5.8 & 3.1 & 6.1 & 7.3 & 9.7 \\
\hline Female & 52.7 & 59.6 & 58.3 & 53.2 & 55.8 & 44.2 \\
\hline Education, less than HS graduate & 30.2 & 49.2 & 46.6 & 30.4 & 40.4 & 57.0 \\
\hline Physically inactive & 24.4 & 30.3 & 37.9 & 23.9 & 33.0 & 41.9 \\
\hline Current smoker & 22.8 & 12.8 & 10.3 & 21.5 & 24.0 & 23.1 \\
\hline Waist circumference, $\mathrm{cm}$ & $96.3(0.3)$ & $98.5(0.8)$ & $96.8(0.9)$ & $95.9(0.3)$ & $99.7(0.7)$ & $103.0(2.2)$ \\
\hline Systolic blood pressure, $\mathrm{mm} \mathrm{Hg}$ & $131.1(0.4)$ & $143.1(1.2)$ & $145.0(1.6)$ & $130.4(0.4)$ & $144.4(1.2)$ & $153.2(2.6)$ \\
\hline Antihypertensive medication use & 21.7 & 49.1 & 63.9 & 21.9 & 43.2 & 52.7 \\
\hline Total cholesterol, mg/dl & $220.3(1.0)$ & $230.8(2.70)$ & $234.6(4.7)$ & $220.6(1.0)$ & $226.7(2.1)$ & $229.0(5.2)$ \\
\hline Diabetes mellitus & 9.5 & 16.4 & 19.9 & 7.6 & 27.6 & 37.7 \\
\hline \multicolumn{7}{|l|}{$\mathrm{CRP}, \mathrm{mg} / \mathrm{l}$} \\
\hline $3-9.9$ & 25.7 & 31.5 & 31.7 & 25.7 & 31.4 & 25.8 \\
\hline$\geq 10$ & 9.4 & 14.3 & 24.2 & 8.7 & 19.6 & 23.3 \\
\hline Serum phosphorus, mg/dl & $3.41(0.01)$ & $3.47(0.03)$ & $3.53(0.04)$ & $3.42(0.01)$ & $3.40(0.02)$ & $3.40(0.06)$ \\
\hline Serum albumin, g/dl & $4.10(0.02)$ & $4.04(0.02)$ & $3.98(0.05)$ & $4.10(0.02)$ & $4.09(0.02)$ & $3.81(0.04)$ \\
\hline Serum $25(\mathrm{OH}) \mathrm{D}, \mathrm{ng} / \mathrm{ml}$ & $28.2(0.3)$ & $28.4(0.5)$ & $26.1(0.7)$ & $28.6(0.3)$ & $25.9(0.4)$ & $23.7(1.3)$ \\
\hline History of stroke & 3.0 & 8.5 & 12.9 & 3.3 & 6.3 & 6.4 \\
\hline History of myocardial infarction & 6.3 & 14.9 & 23.1 & 6.7 & 12.1 & 11.9 \\
\hline
\end{tabular}

Values are either means (standard error) or percentages. HS = High school.

$\mathrm{min} / 1.73 \mathrm{~m}^{2}$ as well as those with ACR levels of $30-299.9 \mathrm{mg} / \mathrm{g}$ and $\geq 300 \mathrm{mg} / \mathrm{g}$ due to the relatively low number of cases in these groups. We calculated hazard ratios for infection-related mortality for participants with (1) eGFR $<60 \mathrm{ml} / \mathrm{min} / 1.73 \mathrm{~m}^{2}$ and ACR $<30 \mathrm{mg} / \mathrm{g}$, (2) eGFR $\geq 60 \mathrm{ml} / \mathrm{min} / 1.73 \mathrm{~m}^{2}$ and $\mathrm{ACR} \geq 30 \mathrm{mg} / \mathrm{g}$, and (3) eGFR $<60 \mathrm{ml} / \mathrm{min} / 1.73 \mathrm{~m}^{2}$ and ACR $\geq 30 \mathrm{mg} / \mathrm{g}$, each compared to the reference group of (4) eGFR $\geq 60 \mathrm{ml} / \mathrm{min} / 1.73 \mathrm{~m}^{2}$ and ACR $<30 \mathrm{mg} / \mathrm{g}$.

All data were analyzed using SUDAAN (version 9.0; Research Triangle Institute, Research Triangle Park, N.C., USA) to account for the complex NHANES sampling design, including unequal probabilities of selection, oversampling, and nonresponse.

\section{Results}

For the current analysis, we excluded 1,784 participants who were missing data for serum creatinine, 25 participants with an eGFR $<15 \mathrm{ml} / \mathrm{min} / 1.73 \mathrm{~m}^{2}, 570$ participants who were missing data for urinary albumin or urinary creatinine, and 8 participants who did not have follow-up information. We included the remaining 7,400 NHANES III participants $\geq 45$ years of age in the analysis. Participants who were excluded due to missing data were older and more likely to be non-Hispanic Black. However, the gender distribution was similar between included and excluded individuals.

\section{Participant Characteristics}

The prevalence of eGFR levels of $\geq 60,45-59.9$ and $<45 \mathrm{ml} / \mathrm{min} / 1.73 \mathrm{~m}^{2}$ were $90.2,7.0$ and $2.8 \%$, respectively. The prevalence of ACR levels of $<30,30-299.9$ and $\geq 300$ $\mathrm{mg} / \mathrm{g}$ were $87.2,11.0$ and $1.8 \%$, respectively. Participants with lower eGFR and higher ACR were older, had less education and were more likely to be physically inactive, taking antihypertensive medication, have diabetes, and a have history of stroke and myocardial infarction (table 1). Additionally, on average, participants with lower eGFR and higher ACR levels had a larger waist circumference, higher levels of systolic blood pressure, total cholesterol and CRP, and lower levels of serum albumin and serum 
Table 2. Hazard ratios for infection-related mortality by eGFR and ACR among adult participants of the Third NHANES

\begin{tabular}{|c|c|c|c|c|c|c|c|c|}
\hline & \multicolumn{4}{|c|}{$\mathrm{eGFR}, \mathrm{ml} / \mathrm{min} / 1.73 \mathrm{~m}^{2}$} & \multicolumn{4}{|c|}{$\mathrm{ACR}, \mathrm{mg} / \mathrm{g}$} \\
\hline & $\geq 60$ & $45-59$ & $<45$ & $\mathrm{p}$ trend & $<30$ & $30-299$ & $\geq 300$ & $\mathrm{p}$ trend \\
\hline \multicolumn{9}{|l|}{ Outcomes } \\
\hline Infection-related deaths, $\mathrm{n}$ & 146 & 37 & 23 & & 155 & 42 & 9 & \\
\hline $\begin{array}{l}\text { Infection-related mortality } \\
\quad \text { (per 1,000 person-years) }\end{array}$ & 1.2 & 4.6 & 10.3 & & 1.3 & 3.1 & 7.0 & \\
\hline Regression model & & HR (95\% CI) & HR (95\% CI) & & & HR (95\% CI) & HR (95\% CI) & \\
\hline Model $1^{\mathrm{a}}$ & 1 (ref.) & $1.47(0.88,2.47)$ & $3.17(1.59,6.30)$ & 0.008 & 1 (ref.) & $1.80(1.11,2.93)$ & $3.79(1.35,10.64)$ & 0.001 \\
\hline Model $2^{\mathrm{b}}$ & 1 (ref.) & $1.45(0.86,2.44)$ & $3.18(1.55,6.51)$ & 0.01 & 1 (ref.) & $1.71(0.99,2.98)$ & $3.28(1.02,10.52)$ & 0.01 \\
\hline Model $3^{c}$ & 1 (ref.) & $1.36(0.81,2.29)$ & $2.36(1.04,5.38)$ & 0.06 & 1 (ref.) & $1.68(0.97,2.92)$ & $2.84(0.92,8.74)$ & 0.02 \\
\hline
\end{tabular}

25(OH)D. Participants with a lower eGFR level had higher serum phosphorus levels, but little difference was observed by ACR level.

Over a median follow-up of 13 years (maximum follow-up: 18), there were 206 deaths attributed to infection: 13 abdominal, 129 respiratory, 51 septicemia, 1 kidney/ genitourinary and 12 cardiac, neurological or other infections (online suppl. Appendix 1).

\section{eGFR and Infection-Related Mortality}

The infection-related mortality rates were higher in individuals with lower baseline eGFR levels (table 2 and online suppl. Appendix 2). Lower eGFR levels were associated with higher hazard ratios for infection-related death after adjustment for age, race/ethnicity, sex and other confounders. Although attenuated, increased hazard ratios for infection-related mortality at lower eGFR levels remained present after multivariable adjustment ( $\mathrm{p}$ trend $=0.01)$ and additional adjustment for log-transformed ACR ( $\mathrm{p}$ trend $=0.06$ ).

\section{ACR and Infection-Related Mortality}

Infection-related mortality rates were higher among participants with higher baseline ACR levels (table 2 and online suppl. Appendix 2). Higher ACR was associated with increased hazard ratios for infection-related mortality after adjustment for age, race/ethnicity and sex. Although the hazard ratios for infection-related mortality remained increased after further adjustment for eGFR, the $95 \%$ CI were wide and included the null. However, the trend for increased infection-related mortality at higher ACR levels was statistically significant ( $\mathrm{p}$ trend $=0.02$ ).
Table 3. Hazard ratios (95\% CI) for infection-related mortality by level of eGFR and albuminuria among adult participants 45 years and older of the Third NHANES

\begin{tabular}{llc}
\hline \multirow{2}{*}{ ACR, $\mathrm{mg} / \mathrm{g}$} & \multicolumn{3}{l}{$\mathrm{eGFR}, \mathrm{ml} / \mathrm{min} / 1.73 \mathrm{~m}^{2}$} \\
\cline { 2 - 3 } & $<60$ & $\geq 60$ \\
\hline$\geq 30$ & $2.59(1.07,6.24)$ & $2.11(1.21,3.66)$ \\
$<30$ & $1.94(1.14,3.30)$ & 1 (ref.) \\
\hline
\end{tabular}

Adjusted for age (modeled using a linear spline), race/ethnicity, sex, smoking status, waist circumference, total cholesterol, hypertension, diabetes mellitus, history of stroke or myocardial infarction, serum $25(\mathrm{OH}) \mathrm{D}$, serum phosphorus and serum albu$\min$.

\section{Cross-Categorization of eGFR/ACR with \\ Infection-Related Mortality}

In a multivariable model incorporating both eGFR and ACR, the hazard ratios for infection-related mortality were higher for those with lower eGFR, higher ACR or both (table 3). Multiplicative interaction between eGFR $<60 \mathrm{ml} / \mathrm{min} / 1.73 \mathrm{~m}^{2}$ and $\mathrm{ACR} \geq 30 \mathrm{mg} / \mathrm{g}$ on infectionrelated mortality was not present $(\mathrm{p}=0.36)$.

\section{Discussion}

In the current study, we report an association between CKD and an increased risk of death from infections. This association was graded across lower eGFR and higher ACR levels and robust to multivariable adjustment for 
multiple potential confounders. Additionally, when considered jointly, individuals with both reduced eGFR and high ACR had an especially high risk for infection-related mortality. Prior studies have reported an increased risk of infection, bacteremia, sepsis and sepsis mortality among patients receiving chronic hemodialysis $[6,7,15]$. The present study extends these previous findings to the substantially larger population of patients with predialysis CKD.

Using provincial administrative data from Calgary, Canada, James et al. [16] identified a higher risk of bloodstream infection in older patients with CKD and subsequent 30-day death. Our study focused on infection-attributed mortality and encompassed all infections, which is clinically relevant since patients are susceptible to and die from a range of infection types - not just bacteremia. In contrast to the 3.2 years of follow-up in the James et al. study, our study followed participants for a median of 14 years, affirming the long-term persistence of infectionmortality risk.

While the high rate of infection among dialysis patients may be related to dialysis-related exposures, CKD patients do not have chronic exposure to hemo- or peritoneal dialysis. Also, the associations of our study persisted even after adjustment for comorbidities such as diabetes and hypertension. These results suggest that other mechanisms may increase the risk for infection among patients with CKD. We were unable to distinguish whether increased infection-related mortality is due to heightened susceptibility or impaired ability to respond to the acute infection.

Numerous studies have linked CKD with all-cause and cardiovascular mortality [3, 4, 17]. In an analysis of 1.1 million adults in the Kaiser Permanente Renal Registry, Go et al. [3] found increasing risks of all-cause mortality and cardiovascular death with worsening eGFR, and attributed these associations with prior cardiovascular disease, inflammatory factors, enhanced coagulopathy, anemia, left ventricular dysfunction, endothelial dysfunction, etc. While our study cannot elucidate the factors linking CKD with heightened infection mortality, infection, sepsis and cardiovascular disease share many of the same hypothesized risk factors and mechanisms. For example, sepsis is characterized by exaggerated inflammatory response to infection [5]. Coagulation and endothelial dysfunction have been implicated in sepsis pathophysiology [18]. Sepsis outcomes are worse in obese patients as well as those with diabetes [19-21]. Cardiovascular disease compromises the host response to sepsis and septic shock, pointing to connections be- tween cardiovascular and infection risk in this population [22]. In this context, cardiovascular mortality may be a competing risk for (i.e. precluding the occurrence of) infection-related mortality. Additional study is warranted to identify the independent and overlapping factors that potentiate infection susceptibility and mortality in CKD patients.

This study has important implications for clinical care of patients with CKD. Strategies to reduce infection may involve the prevention or mitigation of downstream inflammatory responses to infection. For example, avoidance of unnecessary vascular access or invasive procedures may reduce exposure to pathogens. Vaccination may also play an important role in infection prevention. Optimal management of cardiovascular disease risk factors such as hypertension, diabetes, obesity and tobacco use may improve a patient's ability to respond to infection and sepsis. Prior studies suggest that statin use among end-stage renal disease patients may protect against sepsis [23]. Finally, due to very low rates of awareness, detection of CKD is essential [24]. In a study of 3,803 adult with coronary heart disease in the REGARDS cohort, McClellan et al. [25] found that less than $10 \%$ of individuals with CKD (defined by eGFR $<60 \mathrm{ml} / \mathrm{min} / 1.73 \mathrm{~m}^{2}$ ) were aware of their condition.

Despite ample data describing the clinical and physiologic course of acute sepsis, there is relatively little knowledge regarding risk factors for sepsis or potential preventive measures [14]. Prospective population-based studies are necessary to elucidate these risk factors. A broader understanding of infection and sepsis risk factors may lead to key knowledge to reduce CKD mortality.

\section{Limitations}

A major limitation of the current study is the lack of data on nonfatal events. Infection-related mortality captures only the most severe events. Based on the available data, we could not distinguish hospital or institutionally acquired infections. Additionally, the current study relied on the National Death Index for determining cause of death. Although the reliability of mortality follow-up through the National Death Index is very high (98.5\%), this method relies on death certificates which may contain inaccurate information [26].

Certain individuals may have had a secondary infection that played prominent roles in their death. Because the public-use NHANES data set does not have information on contributing causes of death, we relied on the assigned underlying cause alone. The cause of death cat- 
egories may have excluded important infections such as peritonitis, pyothorax or abscesses. Furthermore, for analytic purposes we combined all infections together, but select patients may have responded differently to individual infections. However, we lacked an adequate number of outcomes to ascertain mortality from specific infection groups. While other competing conditions may have influenced the incidence of infectionrelated death, we did not perform a formal competingrisks analysis.

We inferred eGFR and ACR levels from a single baseline visit. Approximately $50 \%$ of individuals with ACR $\geq 30 \mathrm{mg} / \mathrm{g}$ on a single measurement do not have persistent albuminuria [27]. The public-use NHANES data set did not have HIV status available. Because participants in NHANES III were examined at baseline only without follow-up testing, we were unable to ascertain changes in subject characteristics over time. We were also unable to account for changing patterns of immunization or infection over time.

\section{Conclusions}

In conclusion, reduced eGFR and albuminuria were each associated with an increased risk for infection-related mortality in this general population sample of US adults. Efforts are needed to reduce the incidence and mitigate the effects of infections among individuals with CKD.

\section{Acknowledgements}

Funding was provided by an investigator-initiated grant-inaid from Amgen, Inc. to D.W. Amgen did not have any role in the design and conduct of the study, or with the collection, management, analysis or interpretation of the data. H.E.W. received a research support from grant R01-NR012726 from the National Institute of Nursing Research. P.M. had full access to all the data in the study and takes responsibility for the integrity of the data and the accuracy of the data analysis.

\section{Disclosure Statement}

The authors declare no conflicts of interests.

\section{References}

1 Coresh J, Selvin E, Stevens LA, Manzi J, Kusek JW, Eggers P, Van Lente F, Levey AS: Prevalence of chronic kidney disease in the United States. JAMA 2007;298:2038-2047.

$\checkmark 2$ James MT, Hemmelgarn BR, Tonelli M: Early recognition and prevention of chronic kidney disease. Lancet 2010;375:1296-1309.

- 3 Go AS, Chertow GM, Fan D, McCulloch CE, Hsu CY: Chronic kidney disease and the risks of death, cardiovascular events, and hospitalization. N Engl J Med 2004;351: 1296-1305.

-4 Warnock DG, Muntner P, McCullough PA, Zhang X, McClure LA, Zakai N, Cushman M, Newsome BB, Kewalramani R, Steffes MW, Howard G, McClellan WM: Kidney function, albuminuria, and all-cause mortality in the REGARDS (Reasons for Geographic and Racial Differences in Stroke) study. Am J Kidney Dis 2010;56:861-871.

$\checkmark 5$ Dellinger RP, Levy MM, Carlet JM, Bion J, Parker MM, Jaeschke R, Reinhart K, Angus DC, Brun-Buisson C, Beale R, Calandra T, Dhainaut JF, Gerlach H, Harvey M, Marini JJ, Marshall J, Ranieri M, Ramsay G, Sevransky J, Thompson BT, Townsend S, Vender JS, Zimmerman JL, Vincent JL: Surviving Sepsis Campaign: International guidelines for management of severe sepsis and septic shock: 2008. Crit Care Med 2008;36:296327.
6 Sarnak MJ, Jaber BL: Mortality caused by sepsis in patients with end-stage renal disease compared with the general population. Kidney Int 2000;58:1758-1764.

7 Powe NR, Jaar B, Furth SL, Hermann J, Briggs W: Septicemia in dialysis patients: Incidence, risk factors, and prognosis. Kidney Int 1999;55:1081-1090.

-8 Kahn JM, Goss CH, Heagerty PJ, Kramer AA, O'Brien CR, Rubenfeld GD: Hospital volume and the outcomes of mechanical ventilation. N Engl J Med 2006;355:41-50.

-9 Levy MM, Fink MP, Marshall JC, Abraham E, Angus D, Cook D, Cohen J, Opal SM, Vincent JL, Ramsay G: 2001 SCCM/ESICM/ ACCP/ATS/SIS International Sepsis Definitions conference. Intensive Care Med 2003; 29:530-538.

10 Selvin E, Manzi J, Stevens LA, Van Lente F, Lacher DA, Levey AS, Coresh J: Calibration of serum creatinine in the National Health and Nutrition Examination Surveys (NHANES) 1988-1994, 1999-2004. Am J Kidney Dis 2007;50:918-926.

11 Levey AS, Stevens LA: Estimating GFR using the CKD Epidemiology Collaboration (CKD-EPI) creatinine equation: more accurate GFR estimates, lower CKD prevalence estimates, and better risk predictions. Am J Kidney Dis 2010;55:622-627.
12 Loria CM, Sempos CT, Vuong C: Plan and operation of the NHANES II Mortality Study, 1992. Vital Health Stat 1999;38:1-16.

13 Angus DC, Linde-Zwirble WT, Lidicker J, Clermont G, Carcillo J, Pinsky MR: Epidemiology of severe sepsis in the United States: analysis of incidence, outcome, and associated costs of care. Crit Care Med 2001;29: 1303-1310.

14 Wang HE, Devereaux RS, Yealy DM, Safford MM, Howard G: National variation in United States sepsis mortality: a descriptive study. Int J Health Geogr 2010;9:9.

15 Hoen B, Paul-Dauphin A, Hestin D, Kessler M: EPIBACDIAL: a multicenter prospective study of risk factors for bacteremia in chronic hemodialysis patients. J Am Soc Nephrol 1998;9:869-876.

16 James MT, Laupland KB, Tonelli M, Manns BJ, Culleton BF, Hemmelgarn BR: Risk of bloodstream infection in patients with chronic kidney disease not treated with dialysis. Arch Int Med 2008;168:2333-2339.

17 Hallan S, Astor B, Romundstad S, Aasarod K, Kvenild K, Coresh J: Association of kidney function and albuminuria with cardiovascular mortality in older versus younger individuals: The HUNT II study. Arch Int Med 2007;167:2490-2496.

18 Aird WC: Sepsis and coagulation. Crit Care Clin 2005;21:417-431. 
19 Mathieu P, Poirier P, Pibarot P, Lemieux I, Despres JP: Visceral obesity: the link among inflammation, hypertension, and cardiovascular disease. Hypertension 2009;53:577584.

20 Schuetz P, Yano K, Sorasaki M, Ngo L, St Hilaire M, Lucas JM, Aird W, Shapiro NI: Influence of diabetes on endothelial cell response during sepsis. Diabetologia 2011;54:9961003.

-21 Vachharajani V, Vital S: Obesity and sepsis. J Intensive Care Med 2006;21:287-295.
22 Landgarten MJ, Kumar A, Parrillo JE: Cardiovascular dysfunction in sepsis and septic shock. Curr Treat Options Cardiovasc Med 2000;2:451-459.

-23 Gupta R, Plantinga LC, Fink NE, Melamed ML, Coresh J, Fox CS, Levin NW, Powe NR: Statin use and sepsis events in patients with chronic kidney disease. JAMA 2007;297: 1455-1464.

-24 Plantinga LC, Tuot DS, Powe NR: Awareness of chronic kidney disease among patients and providers. Adv Chronic Kidney Dis 2010;17:225-236.

-25 McClellan WM, Newsome BB, McClure LA, Cushman M, Howard G, Audhya P, Abramson JL, Warnock DG: Chronic kidney disease is often unrecognized among patients with coronary heart disease: the REGARDS cohort study. Am J Nephrol 2009; 29:10-17.
26 Williams BC, Demitrack LB, Fries BE: The accuracy of the National Death Index when personal identifiers other than social security number are used. Am J Public Health 1992;82:1145-1147.

27 Coresh J, Astor BC, Greene T, Eknoyan G, Levey AS: Prevalence of chronic kidney disease and decreased kidney function in the adult us population: Third National Health and Nutrition Examination Survey. Am J Kidney Dis 2003;41:1-12. 